12 Johnson KA, Holman LB, Mueller SP, et al. Single photon emission computed tomography in Alzheimer's disease. Arch Neurol 1988;45:392-6.

13 Foster NL, Chase TN, Fedio P, et al. Alzheimer's disease: focal cortical changes shown by positron emission tomography. Neurology 1983;33:961-5.

14 Taboeda E, Dickson D, Horoupian D, Davies P. Clinicopathologic and neurochemical studies of one case of dysphasic dementia. $J$ Neuropathol Exp Neurol 1986;45:323.

15 Morris JC, Cole M, Banker BQ, Wright D. Hereditary dysphasic dementia and the PickAlzheimer spectrum. Ann Neurol 1984;16:455-66.

16 Tissot R, Constantinidis J, Richard J. Picks disease. In: Vinken PJ, Bruyn GW, Klawans HL, Fredriks JAM, eds. Handbook of Clinical Neurology Neurobehavioural disorders. Amsterdam, 1985;46:233-46.

17 Hudson AJ. Amyotrophic lateral sclerosis and its association with dementia, parkinsonism and other neurological disorders: a review. Brain 1981;104:217-47.

18 Salazar AM, Masters CL, Gadjusek DC, Gibbs CJ. Syndromes of amyotrophic lateral sclerosis and dementia: relation to transmissible Creutzfeldt-Jakob disease. Ann Neurol 1983;14:17-26.

19 Wechsler AF, Verity MA, Rosenchein S, Fried I, Scheibel AB. Pick's disease. A clinical, computed tomographic and histologic study with Golgi impregnation observations. Arch Neurol 1982;39:287-90.

20 Brun A. Frontal-lobe degeneration of non-Alzheimer type. 1. Neuropathology. Arch Gerontol Geriatr 1987;6:193-207.

21 Munoz-Garcia D, Ludwin SK. Classic and generalised variants of Pick's disease: a clinicopathological, ultrastructural and immunocytochemical comparative study. Ann Neurol 1984;16:467-80.

Accepted 6 September 1988

\section{Severe aggravation of blepharospasm in Fisher's syndrome}

Sir: Essential blepharospasm has been considered a cranial dystonia caused by a biochemical imbalance of the extrapyramidal system ${ }^{12}$ with no relevant peripheral nervous system contribution. Fisher's syndrome is characterised by external ophthalmoplegia, ataxia and arreflexia and represents a limited form of acute idiopathic polyneuropathy (Guillain-Barré) syndrome. Both processes coincided in a 67 year old male. At 20 years of age he began to suffer occasional involuntary lid closure, more prominent in the right eye, but without disability. These spasms had increased slightly in recent years, often triggered by bright light. After an episode of acute febrile rhinopharyngitis 15 days earlier, over a week he developed severe progressive ataxia, complete external and internal ophthalmoplegia, the eyes remaining in neutral position, ptotic but without diplopia, and general arreflexia. Consciousness was normal. CSF showed 0 cells, glucose $0.68 \mathrm{~g} / 1$ and protein $0.63 \mathrm{~g} / 1$. In the next few days, transitory breathing and swallowing difficulties developed, as well as mild weakness of the facial musculature. In this situation of complete ocular paralysis, the patient made constant gesticulation due to frequent, occasionally sustained, bilateral blepharospasm attacks. This picture regressed to the previous situation after the ophthalmoplegia resolved some months later.

The severe aggravation of facial spasms in our case was striking, well in excess of what could have been expected from the emotional stress of hospitalisation or appearance of new symptoms. A coincidental relation to an improbable midbrain lesion is purely speculative. A lesion located in the midbrain tegmentum was discovered in only one case of Fisher's syndrome ${ }^{3}$ and had not been confirmed in other necropsy cases. On the other hand, in only one case of blepharospasm was a well-localised upper brain stem lesion found. ${ }^{4}$ In our patient, the futility of efforts to counter ocular paralysis and palpebral weakness ( $m$. elevator palpebrae) may have accentuated the actions of antagonist muscles (m. orbicularis oculi). The excess of frustrated central excitation and lack of reciprocal inhibition is considered the EMG pattern of dystonia ${ }^{5}$ and could explain our case.

\section{E GARCIA-ALbEA}

Neurology Service Hospital de Alcalá de Henares

Ctra Alcaláa-Meco

Alcalá de Hemares

28880 Madrid Spain

\section{References}

1 Marsden CD. Blepharospasm-oromandibular dystonia syndrome (Brueghel's syndrome). J Neurol Neurosurg Psychiatry 1976;39:1204-9.

2 Garcia-Albea E, Franch O, Muñoz D, Ricoy JR. Brueghel's syndrome, report of a case with postmortem studies. J Neurol Neurosurg Psychiatry 1981;44:437-40.

3 Derakshan I, Lofti J, Kautman B. Ophthalmoplegia, ataxia and hyporeflexia (Fisher's syndrome). Eur Neurol 1979;18:361-6.

4 Jankovic J, Patel SC. Blepharospasm associated with brainstem lesions. Neurology 1983; 33:1237-40.

5 Rothwell JC, Obeso A, Marsden CD. Pathophysiology of dystonias. In: Desmedt JE Advances in Neurology, vol. 39, ed New York: Raven Press. 1983.851-63.

Accepted 22 September 1988
Orthostatic tremor: diagnostic entity or variant of essential tremor?

Sir: Heilman' described three patients witho orthostatic tremor, that is, tremor of the legs and trunk which commenced shortly after standing but disappeared when walkinges leaning against a support, sitting or lying. Heilman considered orthostatic tremor to be⿳亠丷厂 a distinct neurological entity related to the maintenance of static posture.

Certain features distinguish orthostatic $\overline{\overline{\bar{F}}}$ tremor from classical essential tremor. The oscillation frequency of orthostatic leg tremor has been reported to be between $14 \frac{\mathrm{O}}{\mathrm{c}}$ and $18 \mathrm{~Hz}^{2-4}$ far higher than the frequency range of classical essential tremor.' Further- $\varrho$ more, it has been reported that propranolol, the drug of choice in essential tremor, is ineffective in orthostatic tremor. ${ }^{16}$ Clon- -0 azepam (2-4 mg/day) has been found to be $=$ beneficial in orthostatic tremor ${ }^{146}$ but to be of little benefit in essential tremor. ${ }^{7}$

There is, however, some overlap in the phenomenology of orthostatic tremor and essential tremor. One of Heilman's ortho-? static tremor patients had a concurrent poos. tural tremor of the hands and a famdycu history of essential tremor.' Wee et ${ }^{\circ}{ }^{6} \circ$ described a family in which some membs had a 7-8 Hz tremor of the hands which wasresponsive to propranolol, and others ha⿷匚⿳丨コ丨 6-7 Hz tremor of the legs on standing which was responsive to clonazepam but not beta-blockers.

We describe a patient with a diagnosis $\vec{q} \overrightarrow{\mathrm{c}}$ essential tremor of the hands and legs. Leg tremor, but not hand tremor was successfully treated with clonazepam.

A 53 year old women had a 15 year history of trembling of the legs when standing $\bar{O}$ unsupported. The tremor disappeared on walking or when leaning against a support. There was no tremor at rest or when seated $\vec{B}$ with the legs held outstretched against $\underline{O}$ gravity. For the last 3 years a postural tremor 3 of the hands had been also present. On examination, there were no general or? neurological abnormalities other than tremor (see below). In particular there were no cerebellar or Parkinsonian signs. Her father had a 6 year history of hand tremor. Objective (accelerometric) measures showed a $7.0 \mathrm{~Hz}$ tremor of the distal muscles of the upper limbs when held outstretched in pronated posture. A $6.4 \mathrm{~Hz}$ tremor was present in 을 the proximal muscles of the lower limbs $D$ when standing but was absent during sitting and walking. Diazepam had been tried without success. Propranolol (30 mg/day) was $\sigma$ ineffective but higher doses were not tried. $N$ Primidone initially produced a marked $\mathrm{N}$ 